\title{
Comparison of CNPC and SINOPEC Based on DuPont Analysis
}

WangPeng ${ }^{1}$

\author{
${ }^{1}$ LanZhou City University, Bailie school of petroleum Engineering, LanZhou, China 73000 \\ Author's Email: 935309469@qq.com
}

\begin{abstract}
Based on DuPont analysis, this paper makes a comparative analysis of PetroChina and Sinopec. Firstly, it lists the DuPont analysis framework, collects the data from 2016 to 2019, and then makes a horizontal and vertical analysis on the profitability, operation ability and repayment ability of the two companies and draw relevant conclusions that the prospect of Sinopec is higher than that of PetroChina, and Sinopec is more recommended, and it is believed that Sinopec has long-term investment value.
\end{abstract}

Keywords : DuPont analysis, Financial, Statement analysis, Profitability, Operating capacity.

\section{INTRODUCTION}

CNPC and SINOPEC are two large listed oil companies in China's A-share market. Among them, CNPC attaches great importance to the development and exploration of the upstream, and Sinopec pays more attention to the smelting and sales of the downstream. In 2020, when COVID-19 continued to spread and swept the world, the global economy was facing a recession. The oil industry was also deeply affected. The demand for refined oil in China dropped sharply. Meanwhile, the gross profit rate of downstream oil refining also declined rapidly[1]. In the case of imbalance between supply and demand of refined oil products, this paper compares the operating conditions of the two companies from 2016 to 2019, studies their return on net assets, and takes DuPont analysis as the core to find out which company has a better overall state and can better cope with the crisis. 


\section{DUPONT ANALYSIS FRAMEWORK}

\subsection{Data Arrangement}

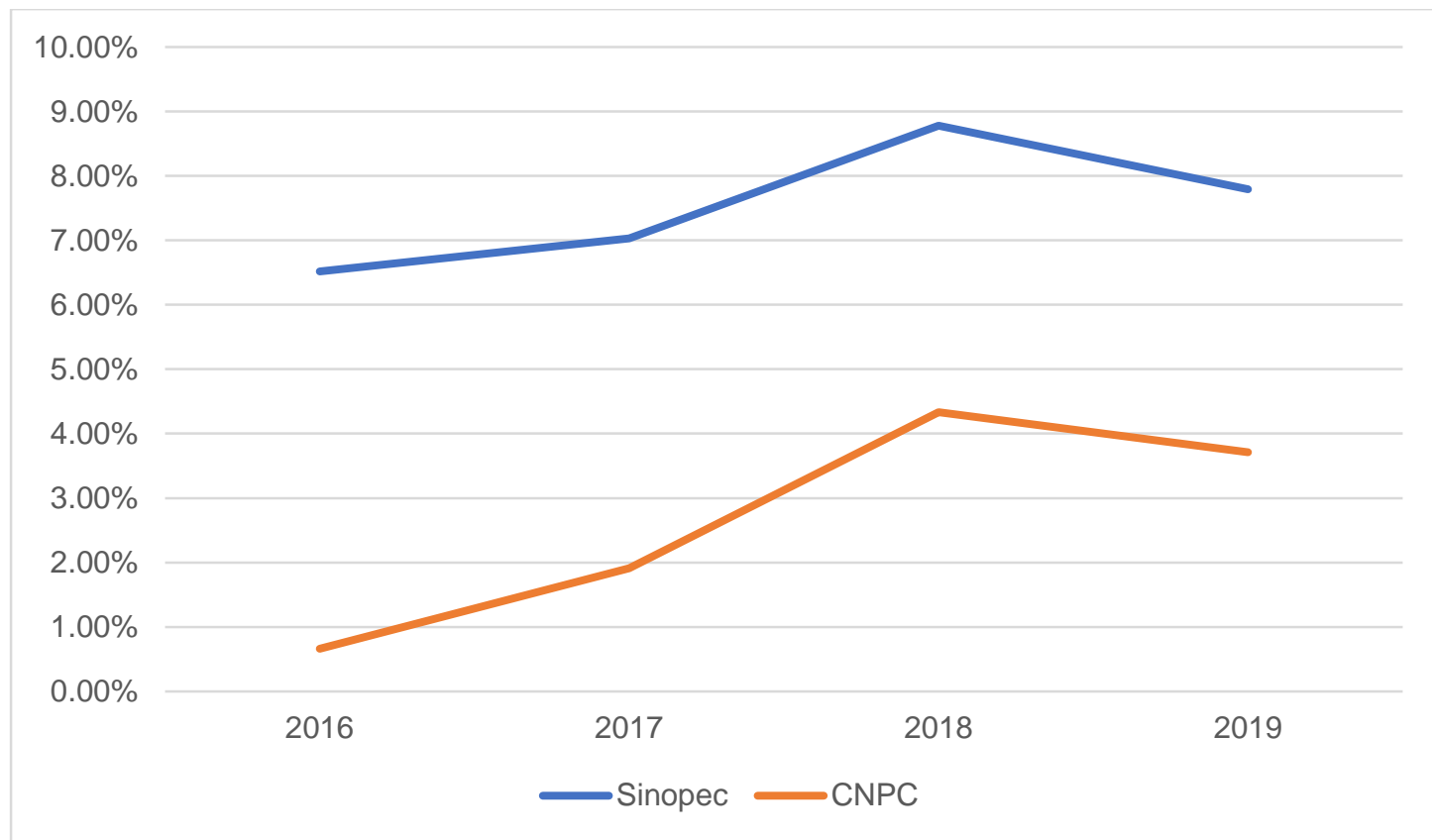

Figure 1. Roe trend chart of CNPC and Sinopec

It can be seen from Figure 1 that the overall roe of Sinopec is higher than that of PetroChina, and the changing trend of the two companies is consistent, indicating that both companies fluctuate with the whole industry and the general environment. The development trend of both companies is good. Both reached the highest value in 2018, and Sinopec's roe reached the highest of $8.78 \%$. PetroChina's growth rate from 2017 to 2018 was relatively large, from $1.91 \%$ to $4.33 \%$.

\subsection{Dupont Analysis Model}

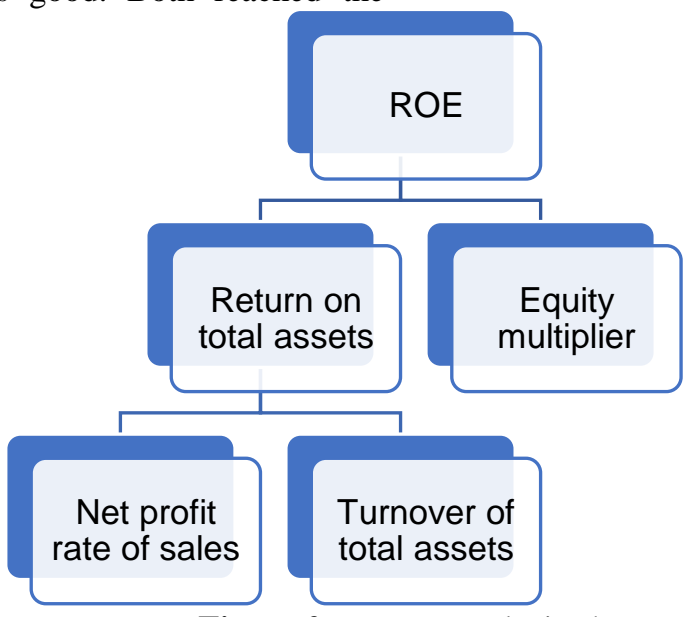

Figure 2. DuPont analysis chart

As shown in Figure 2,

return on total assets $=$ net interest rate $/$ total assets,

equity multiplier $=$ total assets $/$ equity,

net sales interest rate $=$ net profit $/$ operating income,

and turnover rate of total assets = operating income / total assets[2].

\subsection{Dupont Analysis Data}

In 2016, Sinopec's return on net assets was $6.52 \%$, Sinopec's total asset turnover was $1.31 \%$, Sinopec's net sales interest rate was $3.06 \%$, Sinopec's return on total assets was $4.0086 \%$, and Sinopec's equity multiplier was $1.6265 \%$; PetroChina's roe is $0.66 \%$, PetroChina's total asset turnover is $0.68 \%$, PetroChina's net sales interest rate is $1.82 \%$, PetroChina's return on total assets is $1.2376 \%$, and PetroChina's equity multiplier is $0.533 \%$. 
In 2017, Sinopec's return on net assets was $7.03 \%$, Sinopec's total asset turnover was $1.53 \%$, Sinopec's net sales interest rate was $2.98 \%$, Sinopec's return on total assets was $4.5594 \%$, and Sinopec's equity multiplier was 1.54187\%; The return on net assets of PetroChina is $1.91 \%$, the turnover rate of total assets of PetroChina is $0.84 \%$, the net profit rate of PetroChina sales is $1.82 \%$, the return on total assets of PetroChina is $1.5288 \%$, and the equity multiplier of PetroChina is $1.249 \%$.

In 2018, Sinopec's return on net assets was $8.7 \%$, Sinopec's total asset turnover was $1.81 \%$, Sinopec's net sales interest rate was $2.78 \%$, Sinopec's return on total assets was $5.031 \%$, and Sinopec's equity multiplier was $1.7449 \%$; The return on net assets of PetroChina is $4.33 \%$, the turnover rate of total assets of PetroChina is $0.97 \%$, the net profit rate of PetroChina sales is $3.08 \%$, the return on total assets of PetroChina is $2.9876 \%$, and the equity multiplier of PetroChina is $1.4493 \%$ 。

In 2019, Sinopec's return on net assets is $7.79 \%$, Sinopec's total asset turnover is $1.77 \%$, Sinopec's net sales interest rate is $2.43 \%$, Sinopec's return on total assets is $4.3 \%$, and Sinopec's equity multiplier is $1.811 \%$; The return on net assets of PetroChina is $3.71 \%$, the turnover rate of total assets of PetroChina is $0.97 \%$, the net profit rate of PetroChina sales is $2.66 \%$, the return on total assets of PetroChina is $2.58 \%$, and the equity multiplier of PetroChina is $1.4379 \%$.

\section{PROFITABILITY ANALYSIS}

\subsection{Overall Comparison}

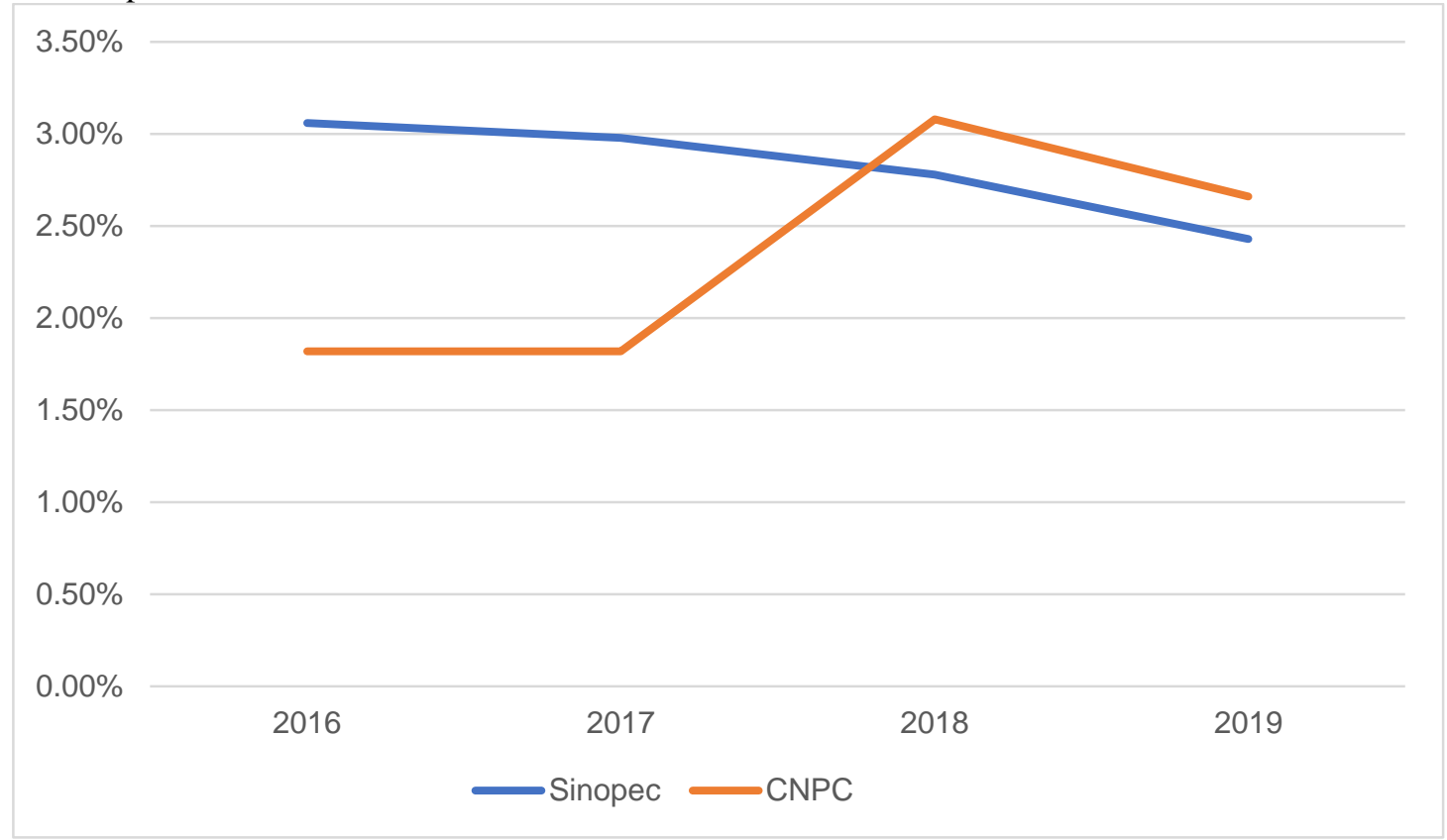

Figure 3. Trend chart of sales net interest rate of PetroChina and Sinopec

The net sales interest rate is the ratio of net interest rate to sales income, which represents the net profit of a yuan sales income and represents the income level.

As can be seen from Figure 3, Sinopec's net sales profit shows a steady downward trend, from $3.06 \%$ in 2016 to $2.43 \%$ in 2019 . After reaching the bottom in 2016, PetroChina's net sales profit rebounded slightly to $3.08 \%$ and then dropped to $2.66 \%$.

\subsection{Petrochina Separate Analysis}

In 2019, PetroChina's operating expenses increased, including procurement, service and other expenses, which increased by $9.3 \%$ year-on-year, due to the increase of PetroChina's procurement costs. In the same year, employee benefits also increased, and the expenditure of employee expenses also increased by $6.9 \%$ year on year[3]
PetroChina's business is divided into four sectors:

- Exploration and production. Due to the overall decline in crude oil prices, but the combined impact of the increase in oil and gas sales, the business income of this sector increased.

Oil refining and chemical industry. The production cost increased due to the increase of crude oil raw material cost, and the operating expenditure increased by $2.6 \%$ year on year.

- Sale. Due to the increase of international trade volume of oil and gas products, the operating revenue has increased, but at the same time, the expenditure on purchased oil products has increased, and the operating expenditure has also decreased.

- Natural gas pipeline. In 2019, PetroChina's expenditure on the natural gas purchase will increase, but at the same time, its sales revenue will also increase. 
However, due to the impact of exchange rate changes, the cost of imported gas increased, and the net loss of imported gas reached 30.71 billion yuan.

- Comprehensive analysis. In 2019, the exploration and production sector will maintain its dominant position in profitability[4]. However, as PetroChina attaches importance to the upstream exploration sector, the sharp decline in the gross profit margin of refining will not have a great impact on it, so the decline in net profit margin of sales is not as big as that of Sinopec.

\subsection{Independent Analysis of Sinopec}

In 2019, Sinopec's turnover increased by $2.6 \%$ yearon-year, but its operating expenses also increased by $2.5 \%$. As Sinopec focuses on downstream smelting and sales, most of its crude oil comes from outsourcing, with a slight increase in outsourcing cost in 2019. However, due to the company's efforts to reduce non productive expenses, and some gas stations and land leasing are accounted for in depreciation and financial expenses, the sales, general and management expenses decreased by $15.7 \%$ year on year. Sinopec is divided into four parts[5]

- Exploration and Development Department. Sinopec will vigorously develop its natural gas business in 2019, and the price of natural gas will also rise. Therefore, the company's total revenue will increase by $5.3 \%$ year on year

Refining division. The sharp reduction of oil prices in 2019 will have a great impact on it. On the premise of lower crude oil procurement and processing

costs, its sales price is also lower. In addition, the overseas transportation and insurance premium is rising, and the price difference of light and heavy crude oil is changing. In 2019, the gross profit rate of oil refining is directly reduced from 366 yuan / ton to 96 yuan / ton. Sinopec still focuses on downstream smelting, so this change has a direct impact on the net profit rate of sales in 2019.

- Marketing and Distribution Division. In 2019 , the sales revenue of oil, diesel and kerosene will decrease significantly. This is mainly due to the sharp reduction of the sales price in 2019.

- Chemical Division. Most of the smelters in this sector are basic organic chemicals, synthetic fiber monomers and polymers, synthetic resins, synthetic fibers, synthetic rubber and chemical fertilizers. However, due to the impact of a maximum price reduction of $18 \%$ and a continuous decline in the gross profit margin of products, this department will also suffer a great impact in 2019.

- Comprehensive analysis. From the perspective of profit distribution in 2019, the refining business unit and marketing and distribution business unit are still the same as those in previous years, accounting for the majority of profits. However, the difference between 2019 and previous years is that the marketing and distribution business unit has replaced the refining business unit to become the most profitable department of the company. This is due to the sharp decline in the gross profit margin of the refining division.

\section{OPERATIONAL CAPABILITY ANALYSIS}

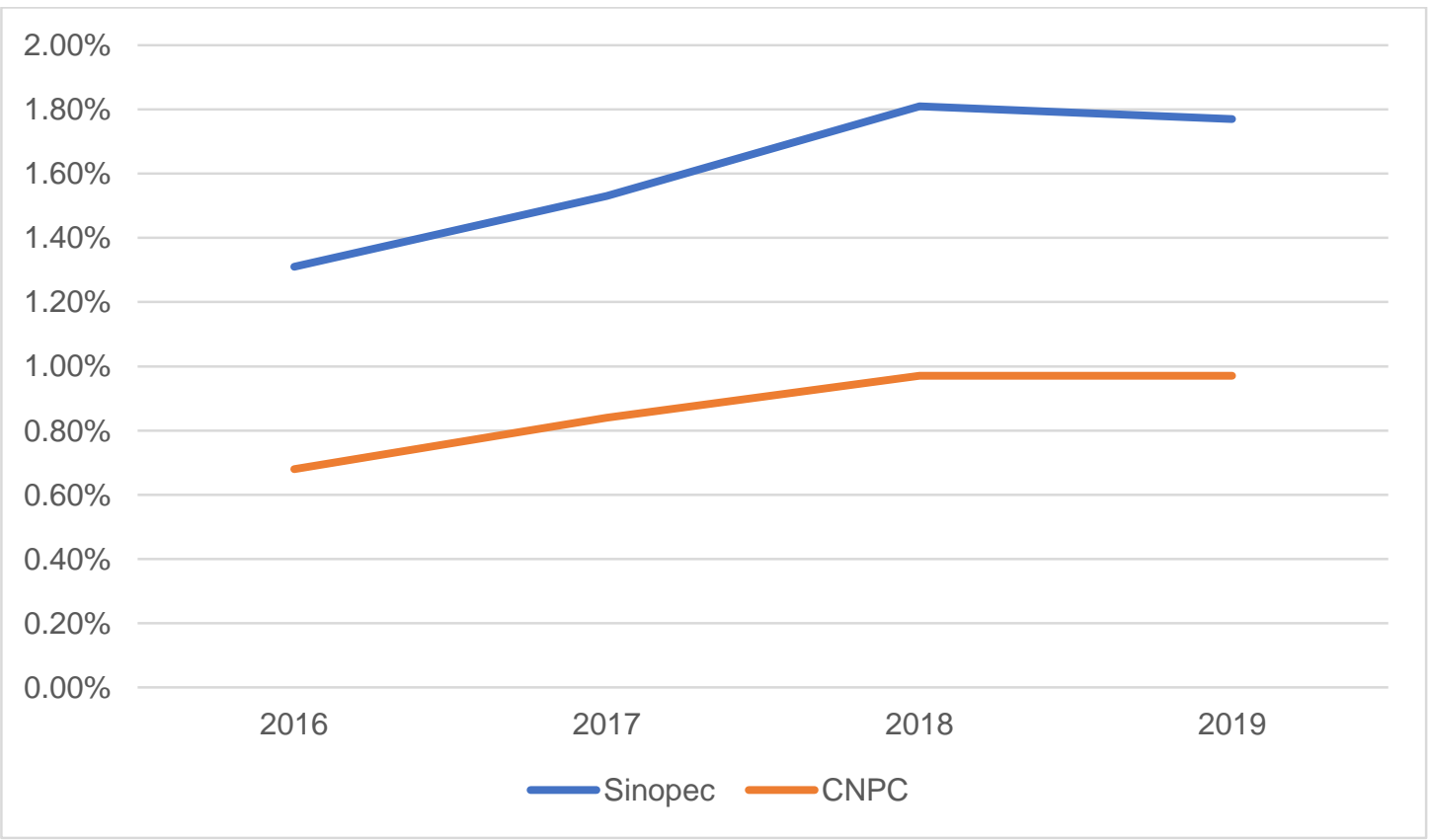

Figure 4. Trend chart of total assets turnover rate of PetroChina and Sinopec 
The turnover rate of total assets is the ratio of net sales revenue and average total assets of an enterprise in a certain period. It reflects the turnover rate of total assets and is an indicator to measure the ratio between the scale of asset investment and the level of sales.

The turnover rate of Sinopec is higher than that of PetroChina and also higher than the average level of the industry. Sinopec pays more attention to downstream sales, so its turnover rate is higher than that of PetroChina. PetroChina's turnover rate remained at $0.97 \%$ in 2018 and 2019, while Sinopec's turnover rate dropped slightly to $1.77 \%$ after reaching the highest point of $1.81 \%$ in 2018 .

\section{SOLVENCY ANALYSIS}

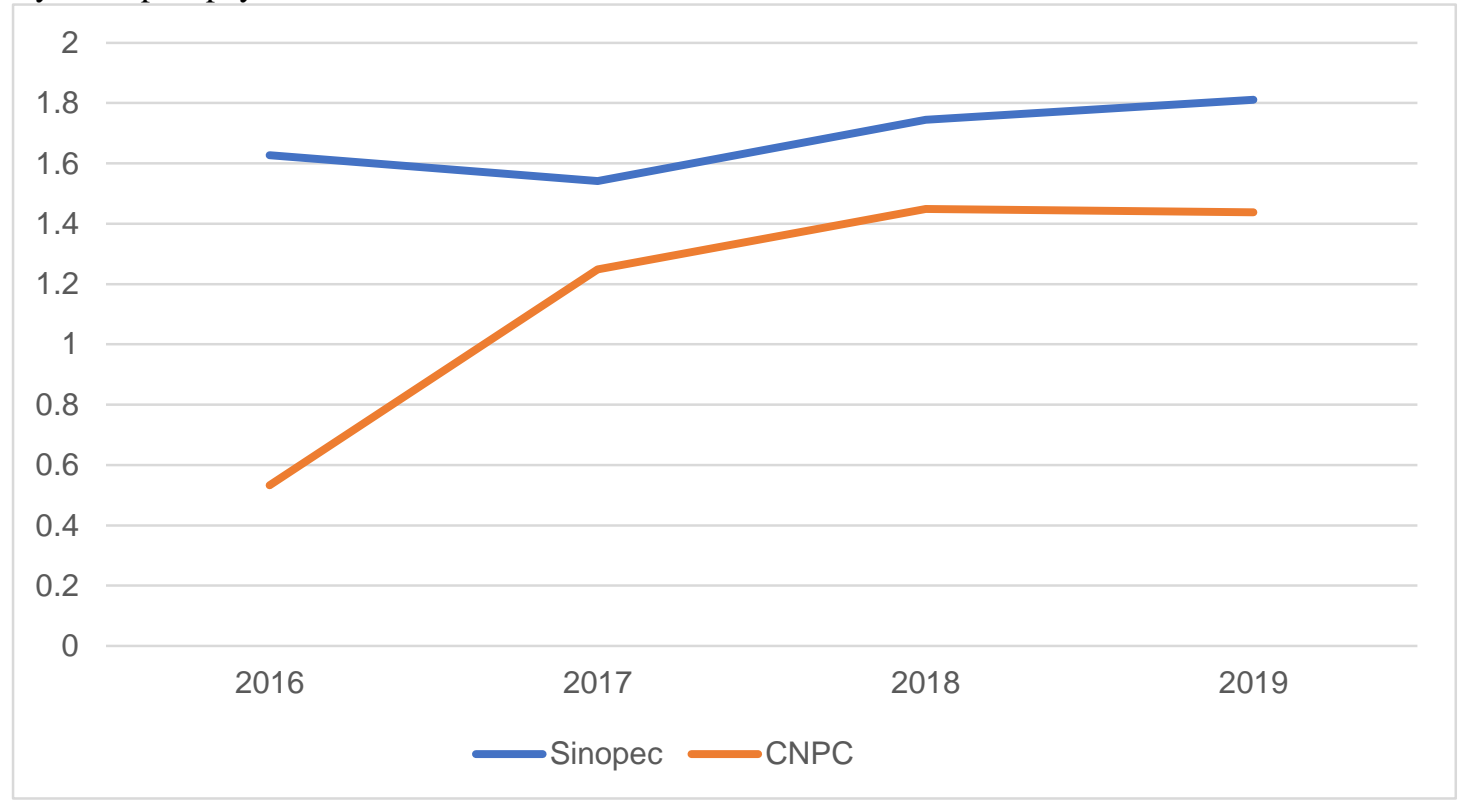

Figure 5. Trend chart of equity multiplier of Sinopec and PetroChina

The equity multiplier represents the degree of debt of an enterprise and reflects the extent to which the company uses financial leverage to carry out business activities. From Figure 5, it can be seen that Sinopec has a greater equity multiplier than CNPC, which indicates that Sinopec's asset liability ratio is higher than that of CNPC, indicating that the company will have more leverage benefits and high risk. PetroChina has less leverage and low risk.

\section{ANALYSIS OF RETURN ON NET ASSETS}

Roe is the most comprehensive financial analysis index and the core of DuPont analysis system. The roe of Sinopec is significantly higher than that of PetroChina, but its influencing factors are different[6]. We can't just look at this index.

This year, the supply and demand of China's oil products are surplus. Sinopec has 30696 gas stations and 22365 PetroChina. Therefore, Sinopec plays a leading role in retail sales in coastal areas. And with the oil price rising this year, the company's performance will rise.

\section{CONCLUSION}

Comprehensive analysis shows that the prospect of Sinopec is higher than that of PetroChina, and Sinopec is more recommended, and it is believed that Sinopec has long-term investment value and pays attention to the risk of falling oil prices.

\section{ACKNOWLEDGMENT}

At the time of the completion of the thesis, I am very grateful to the professor who brought me the ideas and basic knowledge of the thesis. Before the class, I did not have a systematic knowledge of finance. And I am also very grateful to my thesis teacher, she is not tired of correcting me again and again. Finally, I would like to express my deep gratitude to all the teachers who have helped me.

\section{REFERENCES}

[1] Yuan Jianqin. Situation analysis of petroleum industry in 2020 and prospects for 2021 [J]. China Price, 2021(02):21-23.

[2] Wei Zhenhua. Research on DuPont financial analysis system of Listed Companies -- Taking Huadong Computer Co., Ltd. as an example [J]. Modern marketing (Information version),2019(08):28.

[3] Cai Yanhua. Analysis of the profitability of small and medium-sized listed banks based on DuPont analysis [J]. Modern commerce,2020(31):136-137. 
[4] Fan Xiaorun. Special research on return on net assets of Sinopec based on roe [J]. Modern commerce, 2020(34):44-46.

[5] Zhang Siqi. Research on the performance of Sinopec's specialized restructuring and spin off $[D]$. China University of petroleum (Beijing),2018.
[6] Pan Xinlin. Analysis on profitability of listed ecommerce enterprises based on DuPont analysis-Take group A as an example [J]. Investment and Cooperation ,2021(03):36-37. 